\title{
Effect of acute and chronic excesses of dietary nitrogen on blood neutrophil functions in cattle
}

\author{
D. Raboisson, ${ }^{\star} \dagger^{1}$ C. Caubet,${ }^{*} \dagger$ C. Tasca, ${ }^{*} \dagger$ L. De Marchi, $\ddagger$ J. M. Ferraton, $\ddagger$ S. Gannac, $\ddagger$ A. Millet, $\ddagger$ \\ F. Enjalbert,§ F. Schelcher, ${ }^{*} \dagger$ and G. Foucras ${ }^{*} \dagger$ \\ *Université de Toulouse, Institut National Polytechnique (INP), Ecole Nationale Vétérinaire de Toulouse (ENVT), UMR1225, \\ Interaction Hôtes-Agents Pathogènes (IHAP), 31076, Toulouse, France \\ †INRA, UMR1225, IHAP, 31076, Toulouse, France \\ łUniversité de Toulouse, INP, ENVT, Toulouse, France \\ §Université de Toulouse INPT ENVT, UMR1388 Génétique, Physiologie et Systèmes d'Elevage, F-31076 Toulouse, France
}

\begin{abstract}
Excess dietary nitrogen (EDN) is commonly expected in dairy herds, but no data are available regarding its consequences on cattle immunity. In this study neutrophil functions were assessed during EDN in steers. In experiment 1, 4 one-month periods, 4 diets $[16 \%$ crude protein (CP; DM basis), $20 \% \mathrm{CP}$ based on soybean meal, $20 \% \mathrm{CP}$ based on urea, and $24 \% \mathrm{CP}$ based on urea and soybean meal], and 4 steers were included in a crossover design to determine the effects of a chronic excess. In experiment 2, the repercussions of an acute excess were assessed with 2 periods of $10 \mathrm{~d}$, the same 4 steers, and 2 diets containing 14 and $20 \%$ CP. Sampling was done during the fourth week of each period in experiment 1 , and on $\mathrm{d} 0,1,2,3,7$, and 9 of each period in experiment 2. Individual blood biochemistry parameters were measured and neutrophil factors, such as counts, recovery after isolation, surface expression of CD11b and CD62L, phagocytosis, diapedesis, reactive oxygen species (ROS) production, and bacteria killing, were determined. Data were analyzed by general linear models of R, with period, diet or biochemical component, and animal as explanatory variables. The outcome variables were biochemical or immune variables. The variables diet, period, and animal were forced as fixed effects. Data collected over the entire period of experiment 2 were pooled. Several multiples linear regressions or ANOVA were performed and a Bonferroni correction was applied. In experiment 2 (acute EDN), neutrophil counts were negatively associated with nitrogen intake, conversely to CD62L expression. The observed relative neutropenia may be due to neutrophil margination because CD62L-expressing neutrophils are more likely to stick to endothelium. Interestingly, ROS production was changed by EDN: chronic EDN (experiment 1) was
\end{abstract}

Received April 29, 2014

Accepted August 31, 2014.

${ }^{1}$ Corresponding author: d.raboisson@envt.fr negatively associated with opsonized zymozan (OZ)-induced ROS production and acute EDN (experiment 2) with spontaneous ROS production. For chronic EDN, ROS production upon phorbol 12-myristate 13-acetate was not modified, in contrast to OZ stimulation. Decreased ROS production during chronic EDN probably involves the early events leading to ROS production, as $\mathrm{OZ}$ acts through membrane receptors and phorbol 12-myristate 13-acetate directly activates protein kinase $\mathrm{C}$. This is the first study to provide evidence that the modifications of neutrophil functions produced by excess nitrogen depend on the intensity and duration of the excess. Further studies, including epidemiological studies during risk periods, are needed to resolve the issues linked to EDN.

Key words: immunity, dairy cow, nitrogen excess

\section{INTRODUCTION}

In addition to the well-known metabolic diseases of dairy cattle (i.e., subclinical ketosis and subacute ruminal acidosis), excess dietary nitrogen (EDN) is reported as a common event both on pasture- and corn-based diets (Chapa et al., 2001; Tamminga, 2006; Laven et al., 2007). Excess dietary nitrogen refers to both degradable and nondegradable proteins in the rumen and is defined as disequilibrium between protein and energy content of the ration. The ratio of protein to energy intake is a good marker for EDN; plasma or milk urea and ammonia are also common indicators of EDN (Oltner and Witktorsson, 1983; Oltner et al., 1985). Excess dietary nitrogen prevalence has not been reported previously in any dairy area. In 2005 and 2006 , around $20 \%$ of cows had at least 1 value of MUN above $160 \mathrm{mg} / \mathrm{L}$, the main threshold used to identify EDN in France (Raboisson et al., 2012b). Moreover, the consequences of EDN on production and health remain unclear. Excess dietary nitrogen has been associated with poor fertility (Laven and Drew, 1999), and should 
be avoided at least during critical periods of reproduction (Dawuda et al., 2002). Cows are actually able to adapt to high-nitrogen diets within a few days, and fertility is not worsened for cows on pasture even after urea fertilization (Laven et al., 2007; Ordonez et al., 2007). This suggests that chronic and acute EDN may have different effects in cows. The mechanisms that associate conception failure and EDN could be related to an action of urea or ammonia on oocytes (Laven et al., 2007; Ferreira et al., 2011; Gath et al., 2012), but an indirect link through a diminution of immune functions during EDN is not excluded. In addition, an increase in SCC when cows are allowed to pasture is frequently reported. A recent epidemiological survey revealed both negative and positive associations between SCC and milk urea, depending on the time pattern of the relationship (Raboisson et al., 2012b), which suggests that these interactions might be complex.

The evaluation of neutrophil functions often includes, among others, chemotaxis, quantity of L-selectin-positive cells, phagocytosis, reactive oxygen species (ROS) production, as well as the killing ability and the proportion of cells with apoptosis (Martin et al., 1979; Ward and McLeish, 1995; Cendoroglo et al., 1999; Anding et al., 2003; Sardenberg et al., 2006; Zarbock et al., 2006). We hypothesize that some modifications of these neutrophil functions might occur during EDN in cattle due to the increased plasma urea or plasma ammonia. In cattle with EDN, plasma urea and ammonia originate from a ruminal input.

To date, no data are available on the association between EDN and altered immune functions in cattle. Because neutrophils are closely involved in maintaining udder and uterine health and because mastitis and endometritis are suspected to be increased during EDN, the present study was focused on neutrophils. The aim was to describe the effects of chronic and acute EDN on neutrophil-related immune functions by evaluating the ex vivo response of blood neutrophils in dairy steers to various levels of nitrogen in the diet.

\section{MATERIALS AND METHODS}

\section{Animals, Diets, and Sampling}

All animal housing and handling procedures were in accordance with the Guide for the Care and Use of Agricultural Animals in Research and Teaching (FASS, 2010).

Four Holstein steers were used in 2 separate experiments. They were housed in tiestalls equipped with a mattress but without straw. They could have visual but no physical contact, and no other animals were present in the barn. The steers were 22 and 28 mo old and the mean (SD) weights were 664 (16) and 717 (19) $\mathrm{kg}$ in experiments 1 and 2, respectively.

A crossover design was used in both experiments, with 4 steers, 4 diets, and 4 one-month periods in experiment 1 and the same 4 steers, 2 diets, and 2 ten-day periods in experiment 2 (Table 1 ). The 4 diets in experiment 1 were isoenergetic $\left(4.7 \mathrm{MJ}\right.$ of $\mathrm{NE}_{\mathrm{L}} / \mathrm{kg}$ of DM). They contained 16\% CP (CP16), 20\% CP after substituting part of the corn with soybean meal (CP20S) or with urea (CP20U), and 24\% CP after substituting part of the corn with both soybean meal and urea (CP24; Table 2). The 2 diets in experiment 2 were also isoenergetic $(4.50 \mathrm{MJ} / \mathrm{kg}$ of $\mathrm{DM})$ and contained 14 (CP14) or 20\% CP (CP20) after addition of soybean meal and urea. Forage and concentrates were accurately weighed, mixed, and distributed individually at 0800 and $1800 \mathrm{~h}$. Clean water was available ad libitum. Troughs were cleaned before food distribution and refusals were weighed when present. No washout was performed in experiment 1 . Experiments 1 and 2 were separated by a 1-mo washout period with the same diet for all steers (Table 2). Samplings in experiment 2 were carried out on d $0,1,2,3,7$, and 9 after the start of distribution of the CP14 or CP20 diets.

For each steer, blood was sampled on heparinized tubes for biochemistry analysis every $2 \mathrm{~h}$ between the 2 daily meals (0800 and $1800 \mathrm{~h}$ ) on the first day of the fourth week of each period in experiment 1 and on $\mathrm{d} 0$,

Table 1. Experimental design in experiments 1 and 2

\begin{tabular}{|c|c|c|c|c|c|c|c|}
\hline Item & Period & \multicolumn{4}{|c|}{ Diet assignment ${ }^{1}$} & \multicolumn{2}{|c|}{ Sampling } \\
\hline \multirow[t]{3}{*}{ Experiment 1, 4 mo } & 1 & 24 & 16 & $20 \mathrm{U}$ & $20 \mathrm{~S}$ & \multirow{3}{*}{$\begin{array}{c}1 \text { time, } 0800 \text { to } 1800 \mathrm{~h} \text {, } \\
\text { on wk } 4 \\
\text { of each month }\end{array}$} & \multirow{3}{*}{$\begin{array}{l}3 \text { times, } 2100 \mathrm{~h} \text {, } \\
\text { on wk } 4 \\
\text { of each month }\end{array}$} \\
\hline & 3 & 16 & $20 \mathrm{U}$ & $20 \mathrm{~S}$ & 24 & & \\
\hline & 4 & $20 \mathrm{U}$ & $20 \mathrm{~S}$ & 24 & 16 & & \\
\hline Experiment 2, $2 \mathrm{wk}$, twice & 1 & \multicolumn{2}{|c|}{$\begin{array}{l}14 \\
20\end{array}$} & \multicolumn{2}{|c|}{$\begin{array}{l}20 \\
14\end{array}$} & \multicolumn{2}{|c|}{$\mathrm{d} 1,2,3,4,8$ and 10} \\
\hline
\end{tabular}

${ }^{1}$ Diets contained (DM basis) $16 \%$ CP (16), 20\% CP based on soybean meal (20S), $20 \%$ CP based on urea (20U), and $24 \%$ CP based on urea and soybean meal (24). 
Table 2. Diet composition (DM basis) in experiments 1 and 2

\begin{tabular}{|c|c|c|c|c|c|c|c|}
\hline \multirow[b]{2}{*}{ Item } & \multicolumn{4}{|c|}{ Experiment $1^{1}$} & \multicolumn{3}{|c|}{ Experiment $2^{2}$} \\
\hline & CP16 & CP20S & $\mathrm{CP} 20 \mathrm{U}$ & CP24 & $\begin{array}{c}\text { Pretrial, } \\
\text { wash-out }\end{array}$ & CP14 & CP20 \\
\hline \multicolumn{8}{|l|}{ Ingredient, $\mathrm{kg} / \mathrm{d}$} \\
\hline Alfalfa & 13 & 13 & 13 & 13 & 7.5 & 10.0 & 10.0 \\
\hline Hay & 0.0 & 0.0 & 0.0 & 0.0 & 7.5 & 5.0 & 5.0 \\
\hline Corn & 1.8 & 0.3 & 1.8 & 0.3 & 1.5 & 1.3 & 0.0 \\
\hline Soybean meal & 0.4 & 1.9 & 0.4 & 1.9 & 0.5 & 1.0 & 2.3 \\
\hline Urea & 0.0 & 0.0 & 0.21 & 0.21 & 0.0 & 0.0 & 0.17 \\
\hline \multicolumn{8}{|l|}{ Nutrient } \\
\hline CP, \% & 16.1 & 20.1 & 20.0 & 24.0 & 12.10 & 14.10 & 20.0 \\
\hline $\mathrm{NE}_{\mathrm{L}}, \mathrm{MJ} / \mathrm{kg}$ & 4.70 & 4.70 & 4.70 & 4.70 & 4.35 & 4.50 & 4.45 \\
\hline
\end{tabular}

${ }^{1}$ Diets contained (DM basis) 16\% CP (CP16), 20\% CP based on soybean meal (CP20S), 20\% CP based on urea (CP20U), and 24\% CP based on urea and soybean meal (CP24).

${ }^{2}$ Diets contained (DM basis) 14 and $20 \% \mathrm{CP}$.

$1,2,3,7$, and 9 in experiment 2 . The blood samples for evaluation of neutrophil functions were taken on EDTA and acid-citrate-dextrose tubes at $0900 \mathrm{~h}$ on $\mathrm{d} 4$ of the fourth week for experiment 1 . They were taken at 0900 $\mathrm{h}$ on $\mathrm{d} 0,1,2,3,7$, and 9 for experiment 2 . All samples were taken by trained experimenters, from the jugular veins, alternately on the right and left sides, with a 40- $\times 0.9$-mm needle.

\section{Feed Analysis}

Feedstuffs were analyzed for total $\mathrm{N}$ concentration using a Kjeldahl apparatus (Fisher Scientific, Pittsburgh, PA), and $\mathrm{CP}$ concentration was calculated as $\mathrm{N} \times 6.25$. Net energy for lactation was computed from INRA (2007) tables.

\section{Biochemical Analysis}

Blood gases in all samples were measured with a VetStat Electrolyte and Blood Gaz Analyzer (Idexx, Westbrook, ME) and Kasette Electrolyte 8 Plus immediately after sampling. Plasma ammonia, urea, and glucose concentrations were determined with a Vitros 250 (Orto Clinical Chemistry, Issy les Moulineaux, France). Blood $\mathrm{pH}$, blood partial $\mathrm{CO}_{2}$ pressure, plasma sodium, potassium, and chloride concentrations were measured and the plasma bicarbonate concentration was calculated (Jensen and Kahn, 2001). Moreover, plasma copper, zinc, iodine, thyroxin, NEFA, and BHBA, as well as erythrocyte glutathione peroxidase (GSH-Pxe), were measured once for each period and each steer. All the biochemical analyzers were calibrated daily for the accuracy and the repeatability of the measures.

\section{Neutrophil Functions}

Blood counts (QBC-Vet Centrifuge, Idexx) were measured immediately after sampling. Neutrophils were isolated immediately after sampling as previously described (Carlson and Kaneko, 1973). Briefly, neutrophils were separated by centrifugation $(1,000 \times g$ for 20 min at $37^{\circ} \mathrm{C}$ ). After erythrocyte lysis with a hypotonic saline solution, cell concentration was adjusted to $5 \times$ $10^{6}$ cells $/ \mathrm{mL}$ in a Ca- and Mg-free Hanks' balanced salt solution (HBSS). Flow cytometry analyses were performed with a FACScalibur (Becton Dickinson, Franklin Lakes, NJ) flow cytometer with an argon ion laser and a 488-nm excitation wavelength. Cell size and cell granularity were measured using the forward and side scatter parameters, respectively (Nuutila and Lilius, 2005). The neutrophil purity was assessed by flow cytometry using forward and side scatters and CD11b surface staining. For the analysis of cell membrane expression, 2 fluorescent antibody solutions against CD11b and CD62L were prepared. Each trial was done in triplicate and the average value was used. The 3 controls were the Ca- and Mg-free HBSS cell solution alone and the 2 antibody solutions alone.

Diapedesis was evaluated with a Transwell support (MatTek Corporation, Ashland, MA). Opsonized zymosan (OZ), recombinant human interleukin-8 (hrIl8 ), and HBSS were placed in the wells and neutrophils were deposited in the upper chamber. The OZ was prepared as previously described (Roth and Kaeberle, 1981). After incubation $\left(37^{\circ} \mathrm{C}, 30 \mathrm{~min}\right)$, fluorescent beads were added to the vials and the number of cells that had migrated in response to chemotactic products was determined by flow cytometry. Phagocytosis was determined by flow cytometry after incubating the cells with fluorescein isothiocyanate (FITC)-labeled zymosan for $30 \mathrm{~min}$ at $37^{\circ} \mathrm{C}$. Unstained zymosan was used as control to define the autofluorescence background.

Neutrophil ROS were measured by chemiluminescence $(\mathbf{C L})$ in a liquid scintillation counter (Infinite 200, Tecan, Morrisville, NC). Neutrophils $\left(2 \times 10^{6}\right.$ cells $/ \mathrm{mL}$ ) were mixed with $\mathrm{OZ}$ at 30 and $300 \mu \mathrm{g} / \mathrm{mL}$, 
with phorbol 12-myristate 13 -acetate (PMA) at 0.1 and $1 \mu \mathrm{mol} / \mathrm{L}$, or with $50 \mu \mathrm{L}$ of HBSS solution alone. The ROS were identified with luminol $(2 \mathrm{mmol} / \mathrm{L})$. The vials were then placed in the counting chamber for 24 measurement cycles of $5 \mathrm{~min}$ each. Each measure was done in triplicate. The reported values for each animalactivator (OZ or PMA) pair were the averages of triplicates for the mean fluorescence of the 24 measures, after subtracting the background.

Myeloperoxidase (MPO) production was determined as previously described (Quade, 1997). Neutrophils (2 $\times 10^{6}$ cells $/ \mathrm{mL}$ ) were mixed in vials with $\mathrm{CaCl}_{2}$ and $\mathrm{OZ}$ at 3,30 , or $300 \mu \mathrm{g} / \mathrm{mL}$, PMA at $0.01,0.1$, or 1 $\mu \mathrm{mol} / \mathrm{L}, 50 \mu \mathrm{L}$ of HBSS solution alone, or $50 \mu \mathrm{L}$ of cytochalasine $(0.02 \mathrm{mg} / \mathrm{L})$. After incubation, MPO was determined by a colorimetric method after addition of tetramethylenzidine. Each measure was done in triplicate. The optical density (OD) was read with a spectrophotometer at 450 and $650 \mathrm{~nm}$. Values were calculated with the formula: $\left[100 \times\left(\mathrm{OD}_{\text {measured }}-\mathrm{OD}_{\mathrm{H}-}\right.\right.$ $\left.\mathrm{BSS}) /\left(\mathrm{OD}_{\text {cytochalasine }}-\mathrm{OD}_{\mathrm{HBSS}}\right)\right]$.

The bactericidal assay has been described previously (Stevens et al., 1991). Neutrophils were incubated with a Staphylococcus aureus suspension $\left(10^{8}\right.$ bacteria $\left./ \mathrm{mL}\right)$. A standard suspension of Staph. aureus was prepared with five 1:10 dilutions from $10^{8}$ to $6 \times 10^{6}$ bacteria/ $\mathrm{mL}$. After incubation, a monobromobimane reagent was added and OD was measured by spectrophotometry at $560 \mathrm{~nm}$. The relationship between live bacteria and the OD provided by the standard curve for each day of the assay was used to transform the OD observed for each sample into the number of live bacteria remaining after incubation. All assays were performed in experiment 1. Diapedesis, phagocytosis, and MPO measurement were omitted from experiment 2 .

\section{Statistical Analysis}

Data were analyzed with general linear model of $\mathrm{R}$ (version 2.13.1; 2011-07-08; R Development Core Team, Vienna, Austria), including ANOVA or multiple linear models. First, to explain the changes in the biochemical components, each outcome variable "biochemical components" was explained in a distinct model with the explanatory variables "diet" (or "another biochemical components") and "animal" and "period" as covariates. Second, each outcome variable "immune function" was explained in a distinct model with the explanatory variables "diet" (or "biochemical components") and "animal" and "period" as covariates. Diet, period, and animal were considered as fixed effects. When assayed more than once during the study period, the biochemical variables were (1) the average daily value, representing the area under the curve determined by the 8 values from the 8 samplings during the $10 \mathrm{~h}$ between the meals and designated mean value, and (2) the maximum value, read at the peak of the curve, and designated maximum value. The blood mean value was calculated once per diet, period, and animal in experiment 1 , and once per day per diet, period, and animal in experiment 2 . The variable day was added in the models of experiment 2 , but due to the lack of significance data for the $6 \mathrm{~d}$ were pooled. Thus, the models used in experiments 1 and 2 were similar. All models were univariable and a Bonferroni correction was applied for experiments 1 and 2 separately.

\section{RESULTS}

\section{Biochemistry and Hematocrit}

Among biochemical components measured, only mean plasma ammonia and urea (experiments 1 and 2) differed between animals, periods, or diets (Figure 1). In experiment 1 , mean plasma ammonia was significantly higher for CP20U and CP24 than for CP16 and CP20S, and mean plasma urea was significantly higher for CP20S, CP20U, and CP24 than for CP16. The same effects and same patterns were observed when max plasma ammonia was analyzed instead of mean plasma ammonia. In contrast, max plasma ammonia increased linearly when the CP content increased from CP16 to CP24 (data not shown). In experiment 2, mean plasma ammonia and urea were significantly higher for CP20 than for CP14. The same effects were observed when max plasma urea and ammonia were analyzed instead of mean plasma urea and ammonia (data not shown).

When the relationships among the biochemical parameters were analyzed with animal and period as covariates, a significant $(P<0.001)$ and positive association was detected (1) between mean plasma urea and ammonia, between mean plasma urea and max plasma ammonia, and between mean plasma ammonia and max plasma urea for experiments 1 and 2 , and (2) between max plasma ammonia and urea for experiment 2. Mean blood $\mathrm{pH}$, mean plasma bicarbonates, and mean blood partial $\mathrm{CO}_{2}$ pressure were positively correlated in both experiments. No other biochemical variables were associated with diet or with another biochemical variable. The BHBA concentrations varied from 0.1 to $0.2 \mathrm{mM}$, GSH-Pxe from 325 to $500 \mathrm{IU} / \mathrm{g}$ of $\mathrm{Hb}$, and NEFA from 0.05 to $0.15 \mathrm{mM}$. Packed cell volume ranged from 26 to $33 \%$ and was not associated with period, diet, or biochemical components.

\section{Neutrophil Functions}

In some of the models involving a neutrophil function as the outcome variable, the explanatory variables 

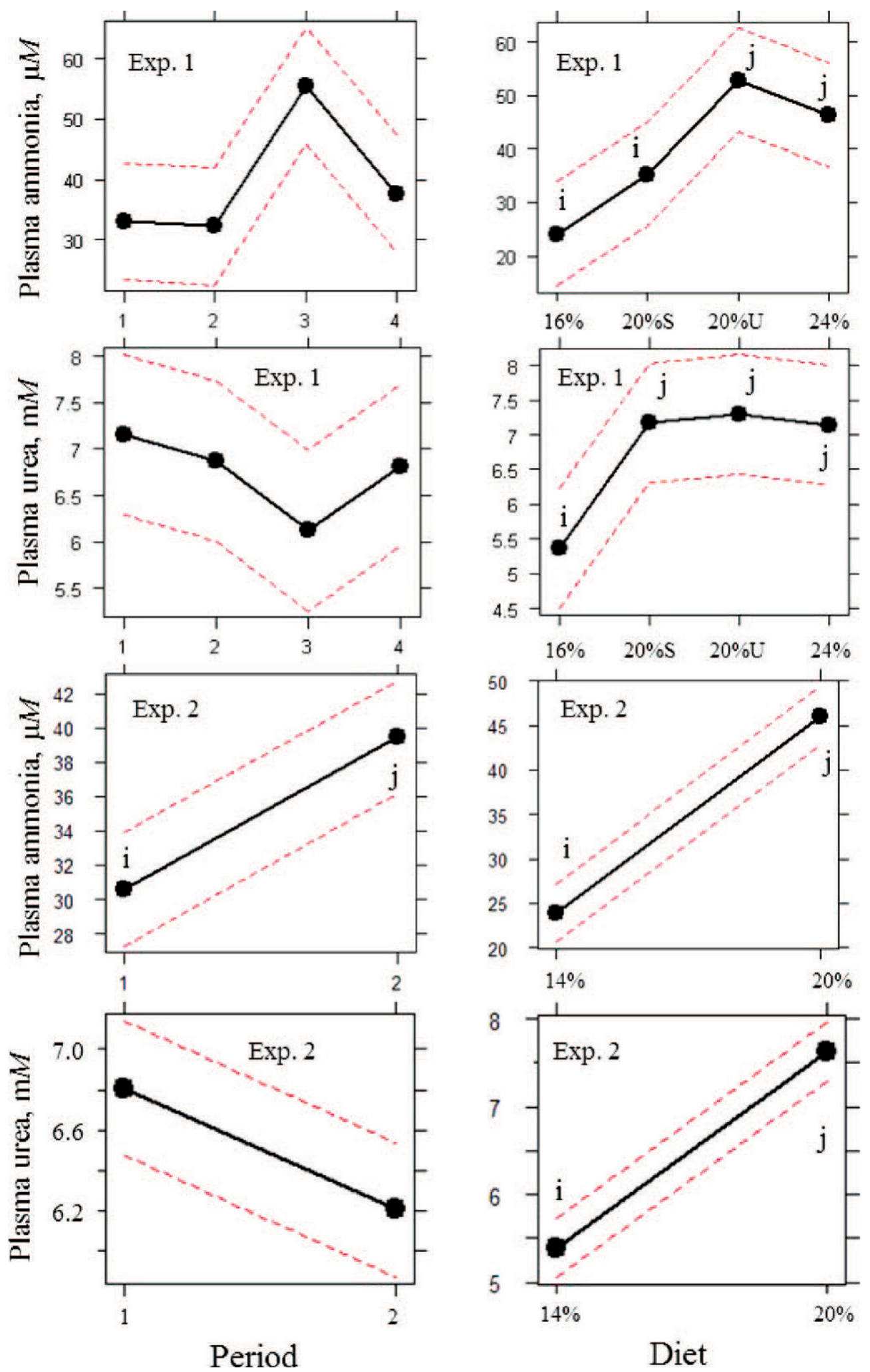

Figure 1. Association between plasma ammonia or urea and animal, period, or diet in experiments 1 and 2. Plots represent the association between each outcome variable (plasma ammonia or urea) and the variables animal, period, and diet. Dotted lines represent the 95\% CI of the estimates. Plasma ammonia and urea represent the mean value between the 2 daily meals (0800 and 1800 h). For diets, percentages indicate the level of CP. For $20 \%$ CP, soybean meal (S) and urea (U) refer to the main contributor of nitrogen. Exp. 1= experiment 1; Exp. $2=$ experiment 2. Letters $(\mathrm{i}, \mathrm{j})$ within plots refer to statistical differences $(P<0.001)$. Color version available in the online PDF. 
animal and period were significant, indicating that these parameters were sources of variation and were thus carefully controlled. Indeed, variability of the neutrophil functions was particularly high between animals (results not shown). A summary of the significant associations is presented in Table 3. The coefficient of determination $\left(\mathrm{R}^{2}\right)$ of the models varied between 50 and $80 \%$ for all the significant models, indicating that 50 to $80 \%$ of the variability of the outcome variable is explained by the explanatory variables.

The average number of blood neutrophils was 0.88 $\times 10^{9}\left(\mathrm{SD}=0.06 \times 10^{9}\right)$ and $3.01 \times 10^{9}(\mathrm{SD}=0.72$ $\times 10^{9}$ ) cells $/ \mathrm{L}$ in experiments 1 and 2 , respectively. No association between the counts and diets or blood components was observed in experiment 1 . In experiment 2, the blood neutrophil count decreased for CP20 compared with CP14 and decreased linearly, whereas mean plasma urea increased (Figure 2). A positive association was also noticed between counts and blood BHBA (data not shown). After isolation by Percoll gradient, neutrophil purity was higher than $90 \%$ in all samples in both experiments. The CD11b-positive cells represented 88.3 and $90.5 \%$ in experiments 1 and 2, respectively. Cell purity was never associated with diet. Cell purity increased with mean plasma bicarbonates in experiment 1 (Figure 2).

The CD11b expression was not associated with diet or any blood component in experiments 1 and 2 , but decreased with increased blood BHBA in experiment 2 (Table 3 ). The CD62L expression was not associated with diet in experiment 1 . In experiment 2, CD62L expression was positively associated with mean plasma urea (Figure 2), but negatively associated with BHBA (Table 3). Moreover, the CD62L expression was significantly higher for CP20U than for CP14 and it was positively associated with mean plasma ammonia before the Bonferroni correction was applied. Models did not remain significant with the Bonferroni correction.

Spontaneous and hrIl-8 or OZ-induced diapedesis (experiment 1) was not affected by diet or associated with any blood biochemical variable. For phagocytosis, although the percentage of neutrophils that engulfed yeast particles was low $(2.18,2.46,2.31$, and $2.29 \%$ for CP16, CP20S, CP20U, and CP24, respectively), and it varied significantly $(P<0.05)$ between $\mathrm{CP} 16$ and CP20S.

In experiment 1, OZ-induced mean CL (30 or 300 $\mu \mathrm{g} / \mathrm{mL}$ ) was lower for CP20S, CP20, and CP24 than for CP16 (Figure 3). It was negatively associated with mean plasma ammonia and urea (Figure 3), max plasma ammonia $(P<0.001)$ and urea $(P<0.001$; data not shown), and GSH-Pxe (Table 3). The PMA-induced CL $(0.1$ or $1 \mu M)$ was not associated with diet or any biochemical component. In experiment 2, spontaneous mean CL was lower for CP20 than for CP14, in spite of the lack of differences between diets for both $\mathrm{OZ}$ and PMA.

The MPO activity did not differ between diets and was not associated with any blood parameter (experiment 1). The mean bactericidal activity was 79.2 (SD $=10)$ and $86.2 \%(\mathrm{SD}=9)$ for experiments 1 and 2 , respectively. No association was reported between bactericidal activity and diets or blood components in either

Table 3. Summary of the diet or blood component associations with neutrophil functions ${ }^{1}$

\begin{tabular}{|c|c|c|c|c|c|c|c|c|}
\hline Diet & 1 & & 个*** & $\uparrow * * *$ & & & & \\
\hline \multirow[t]{2}{*}{ Counts } & 1 & & & & & & & \\
\hline & 2 & $\downarrow * *$ & & $\downarrow * *$ & & & $\uparrow * * *$ & \\
\hline \multirow[t]{2}{*}{ Purity } & 1 & & & & $\uparrow * *$ & & & \\
\hline & 2 & & & & & & & \\
\hline \multirow[t]{2}{*}{ CD62L } & 1 & & & & & & & \\
\hline & 2 & & & 个** & & & $\downarrow * * *$ & \\
\hline OZP-induced $\mathrm{CL}^{2}$ & $\begin{array}{l}1 \\
2\end{array}$ & $\downarrow * * *$ & $\downarrow * * *$ & $\downarrow * * *$ & & & & $\downarrow *$ \\
\hline \multirow[t]{2}{*}{ Spontaneous CL } & 1 & & & & & & & \\
\hline & $\begin{array}{l}2 \\
1\end{array}$ & $\downarrow * *$ & & & & & & \\
\hline
\end{tabular}

${ }^{1}$ All the trends in variations (arrows) refer to an increase in the blood component or in the CP level of the diet (16 to $20 \%$ based on soybean meal, $20 \% \mathrm{CP}$ based on urea, or $24 \% \mathrm{CP}$ based on soybean meal and urea in experiment 1; and 14 to $20 \% \mathrm{CP}$ in experiment 2).

${ }^{2} \mathrm{CL}=$ chemiluminescence; GSH-Pxe = erythrocyte glutathione peroxidase; OZ = opsonized zymosan.

$*=P<0.05 ; * *=P<0.01 ; * * *=P<0.001$. 

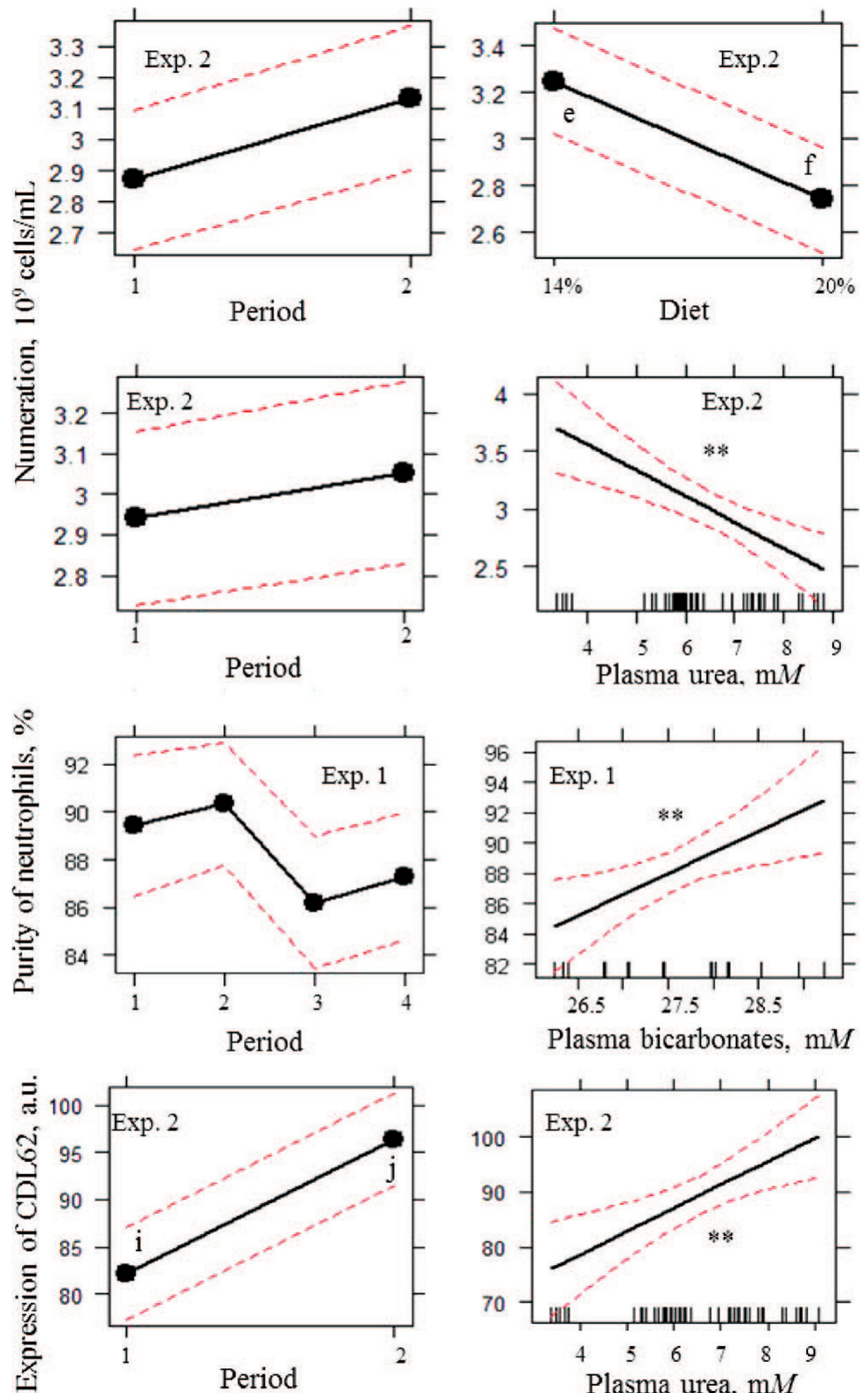

Plasma bicarbonates, $\mathrm{m} M$

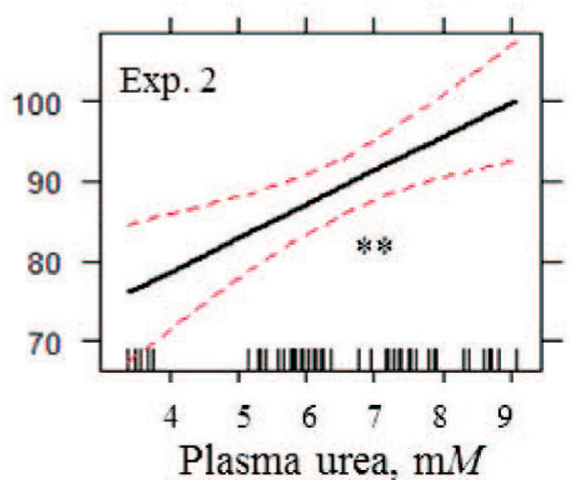

Figure 2. Association between blood neutrophil count, neutrophil purity, and expression of CD62L and animal, period, diet, or biochemical variables in experiments 1 and 2. Plots represent the association between blood neutrophil count, purity, or expression of CD62L (outcome variables) and the variables animal, period, and diet or biochemical. Dotted lines represent the 95\% CI of the estimates. Plasma urea and blood bicarbonates represent the mean value between the 2 daily meals $(0800$ and $1800 \mathrm{~h}$ ). For diets, percentages indicate the level of crude protein Exp. $1=$ experiment 1 ; Exp. $2=$ experiment 2 ; a.u.: arbitrary units.. Letters $(\mathrm{e}, \mathrm{f}=P<0.01 ; \mathrm{i}, \mathrm{j}=P<0.001)$ within plots refer to statistical differences for categories. ${ }^{* *}=P<0.01$. Color version available in the online PDF. 
experiment, except for mean plasma glucose (negative relationship) in experiment 2 (Figure 3 ).

To sum up, acute EDN was negatively associated with blood neutrophil count and positively associated with CD62L expression. The ROS production was reduced during chronic EDN when induced by OZ, whereas spontaneous ROS production was higher during acute EDN. This indicates different repercussions depending on the duration and intensity of EDN.

\section{DISCUSSION}

Altogether the present results show that acute and chronic EDN have different effects on neutrophil functions. The main result from experiment 2 indicates that acute EDN is negatively associated with blood neutrophil count and purity upon isolation, but positively associated with CD62L expression. $\beta$-Hydroxybutyrate is also positively associated with blood neutrophil count, but negatively with CD62L expression. The membrane receptor CD62L, also named L-selectin, is involved in the first step of diapedesis and facilitates the rolling of cells along the endothelium. Because neutrophils expressing CD62L are more likely to be halted on the vascular endothelium cell wall, the proportion of marginalized neutrophils is likely to increase, resulting in greater expression of CD62L and the induction of moderate neutropenia. Indeed, acute EDN probably favors neutrophil attachment, the first step in diapedesis. Moderate changes in blood neutrophil count or CD62L expression were observed (e.g., from 10 to $33 \%$ ), and further research is needed to assess the biological consequences of these observations. This is all the more necessary because the contrary relationship was reported for uremic syndrome in experimentally induced high plasma urea concentrations in mice. Nephrectomized hyperuremic mice exhibited decreased CD62L expression on neutrophils compared with control mice (Zarbock et al., 2006). In this latter study, plasma urea attained values up to $9.2 \mathrm{~m} M$, which is much higher than those reported here and may explain the discrepancy between the observations under the 2 conditions. In cattle, current results (increased CD62L expression with acute EDN) are also in accordance with the reported increase in SCC when milk urea increased on the same test day (Raboisson et al., 2012b). Increased CD62L expression on neutrophils may indeed increase the rate of diapedesis to the mammary tissue and, thus, the neutrophil content of milk during acute EDN. Such a mechanism may partly explain the increased SCC often observed during return to pasture and reported by practitioners. Further investigation is needed to validate this hypothesis.
In experiment 1 , blood acid-base balance was associated with purity (Table 3 ). Higher blood $\mathrm{pH}$ has been reported to be linked to high plasma ammonia concentrations (Raboisson et al., 2012a).

The second main result is that chronic EDN depressed the ROS production induced by microbial particles, as revealed by a diminished OZ-induced CL. Moreover, acute EDN reduced the spontaneous production of ROS, even though this association was not observed for plasma ammonia or urea. The OZ-induced ROS production, conversely to PMA-induced ROS production, was decreased during chronic EDN. This implies that the negative effect of EDN on ROS production involves the initial steps in the ROS production cascade, notably at the cell surface or during particle phagocytosis. Indeed, $\mathrm{OZ}$ acts through membrane receptors, such as toll-like receptor-2, unlike PMA, which acts directly on protein kinase $\mathrm{C}$. The production of MPO was not identified as a limiting factor of ROS production in experiment 1 .

The conclusion regarding phagocytosis is not as clear as for the other parameters. Phagocytosis was not associated with chronic EDN in the present study (experiment 1); a difference was only apparent for CP20S compared with CP16 and the percentages only differed by $12 \%$. This is in accordance with results obtained in dialyzed hyperuremic humans where phagocytosis was unaffected (Anding et al., 2003). Diapedesis and chronic EDN were not associated.

Associations between neutrophil functions and blood BHBA or GSH-Pxe should be considered with caution. Despite their significance, the ranges of values are quite narrow and within the normal range, and the biological significance of such results is debatable. However, such associations are in agreement with the well-known association between neutrophil functions and ketone bodies (Suriyasathaporn et al., 2000) and antioxidant status (Arthur et al., 2003).

The design (crossover) and statistical method (particularly with animal as a fixed effect) were adapted to the small number of animals included in our study. Individual variations in neutrophil functions were very high. In contrast, the use of previously trained steers made it possible to reduce any bias linked to sample collection, such as blood count, and the formula changes reported in stressed cattle. The period effect was sometimes significant. This should not be interpreted as a carry-over effect from period 1 to 2 , but as an adjustment to daily variations in the base levels of the immune response. Indeed, all neutrophil functions were evaluated on the day of sampling. Several models were significant before the Bonferroni correction. Such a correction was needed so as to exclude the risk of a high type 1 error when looking at the whole results at 

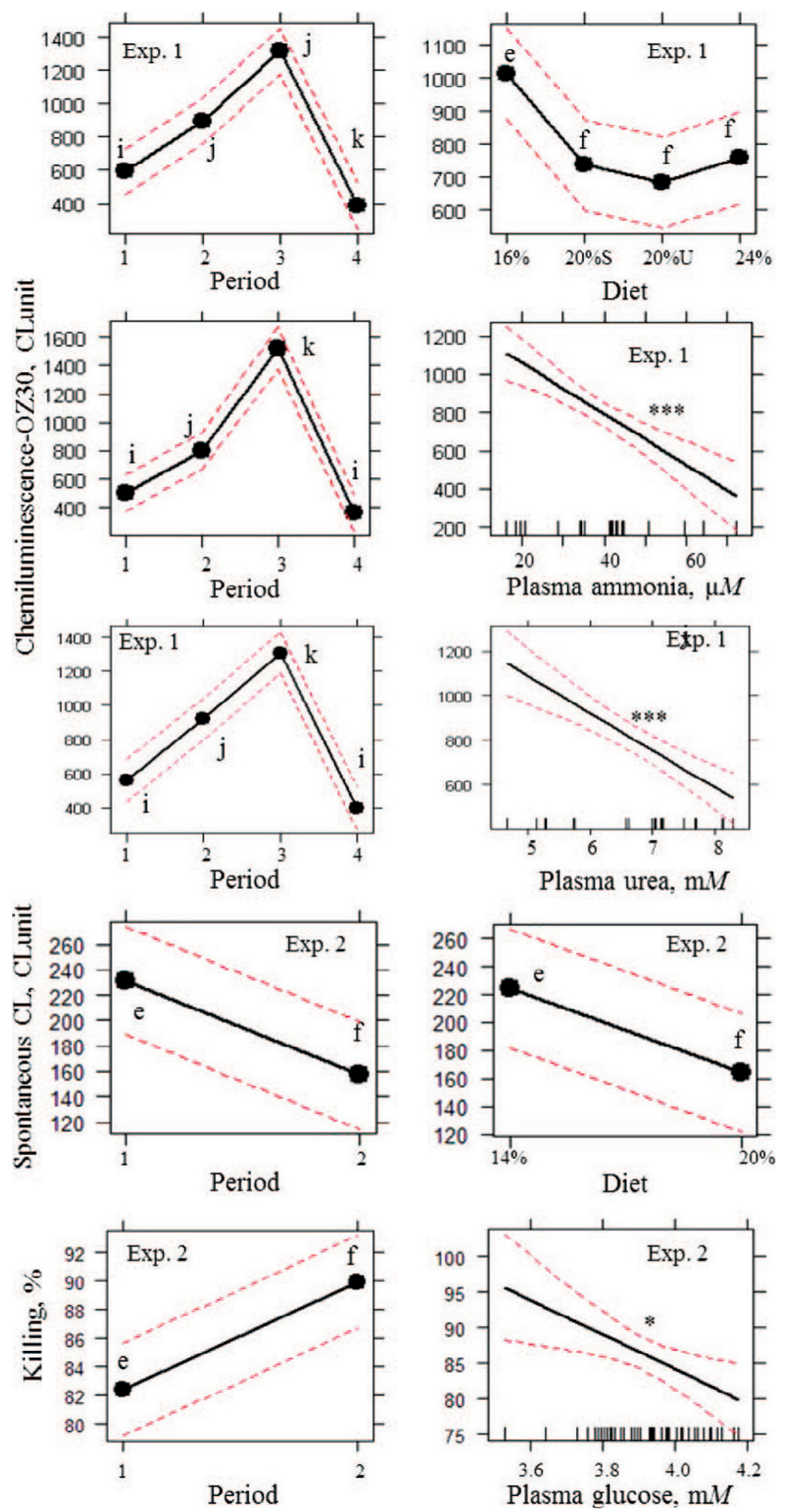

Figure 3. Association between chemiluminescence (reactive oxygen species production) or bactericidal activity (killing) and the variables animal, period, diet, or biochemical in experiment 1 and 2. Plots represent the association between reactive oxygen species production or killing (outcome variable) and the variables animal, period, diet, or biochemical. Dotted lines represent the 95\% CI of the estimates. Plasma urea and ammonia and blood $\mathrm{pH}$ represent the mean value between the 2 daily meals $(0800$ and $1800 \mathrm{~h})$. For diets, percentages indicate the level of CP. For $20 \% \mathrm{CP}$, soybean meal (S) and urea (U) refers to the main contributor of nitrogen. Exp. $1=$ experiment 1 ; Exp. $2=$ experiment 2 . Letters $(\mathrm{e}, \mathrm{f}=P<0.01 ; \mathrm{i}-\mathrm{k}=P<0.00) 1$ within plots refer to statistical differences for categories. ${ }^{*}=P<0.05 ; * * *=P<0.001$. Color version available in the online PDF. 
a glance. Yet, the present results may have excluded some interesting results because of the very restrictive correction used. The models significant before the Bonferroni correction and not significant thereafter were mostly related to the association between immune parameters and blood acid-base balance, plasma potassium, or plasma glucose.

Because blood neutrophils were used in the present study, extrapolations to neutrophils recruited on the site of infection must be made with caution. For example, neutrophils found in milk were reported to have a lower PMA-induced CL than blood neutrophils (Mehrzad et al., 2002). Moreover, during bacterial infection, locally released cytokines induce activation and an increase in adherence, phagocytosis, and bacteria killing (Smith, 1998). The present study is based on ex vivo neutrophil evaluation, and the ranges of values for all blood biochemical parameters were very close to those obtained in the field situation. In contrast, many in vitro evaluations have been based on very different biochemical concentrations from the physiological conditions. Ex vivo protocols do not permit identification of the origin of the function change, as indicated by the fact that several biochemical variables were similarly associated with a change in a given neutrophil function.

\section{CONCLUSIONS}

The current work shows that acute and chronic EDN seem to act differently on neutrophil functions. The EDN may alter the capacity of the bovine immune system to respond to bacterial infections. During acute EDN, blood neutrophil count decreased and CD62L expression increased. Spontaneous CL and OZ-induced CL decreased during acute EDN and chronic EDN, respectively. No differences were seen for chemotaxis, diapedesis, phagocytosis, and MPO production during chronic EDN. At this step of the investigation, no mechanism or biochemical component could be identified that would explain the observed changes in neutrophil count or functions. However, these results are of great interest for the livestock and dairy industry and suggest that a diminution of immunity against bacterial infections may be prevented by controlling the content of nitrogen in the diet. Further research, including epidemiological studies, is needed to determine whether EDN is linked to health and performance in cows, perhaps through modulation of immune responsiveness.

\section{REFERENCES}

Anding, K., P. Gross, J. M. Rost, D. Allgaier, and E. Jacobs. 2003. The influence of uraemia and haemodialysis on neutrophil phagocytosis and antimicrobial killing. Nephrol. Dial. Transplant. 18:2067-2073.
Arthur, J. R., R. C. McKenzie, and G. J. Beckett. 2003. Selenium in the immune system. J. Nutr. 133:1457S-1459S.

Carlson, G. P., and J. J. Kaneko. 1973. Isolation of leukocytes from bovine peripheral blood. Proc. Soc. Exp. Biol. Med. 142:853-856.

Cendoroglo, M., B. L. Jaber, V. S. Balakrishnan, M. Perianayagam, A. J. King, and B. J. Pereira. 1999. Neutrophil apoptosis and dysfunction in uremia. J. Am. Soc. Nephrol. 10:93-100.

Chapa, A. M., M. E. McCormick, J. M. Fernandez, D. D. French, J. D. Ward, and J. F. Beatty. 2001. Supplemental dietary protein for grazing dairy cows: Reproduction, condition loss, plasma metabolites, and insulin. J. Dairy Sci. 84:908-916.

Dawuda, P. M., R. J. Scaramuzzi, H. J. Leese, C. J. Hall, A. R. Peters, S. B. Drew, and D. C. Wathes. 2002. Effect of timing of urea feeding on the yield and quality of embryos in lactating dairy cows. Theriogenology 58:1443-1455.

FASS. 2010. Guide for the Care and Use of Agricultural Animals in Research and Teaching. 3rd ed. Federation of Animal Science Societies (FASS), Champaign, IL.

Ferreira, F. A., R. G. Gomez, D. C. Joaquim, Y. F. Watanabe, L. A. de Castro, and M. Paula. Binelli, and P. H. Rodrigues. 2011. Short-term urea feeding decreases in vitro hatching of bovine blastocysts. Theriogenology 76:312-319.

Gath, V. P., M. A. Crowe, D. O'Callaghan, M. P. Boland, P. Duffy, P. Lonergan, and F. J. Mulligan. 2012. Effects of diet type on establishment of pregnancy and embryo development in beef heifers. Anim. Reprod. Sci. 133:139-145.

INRA. 2007. Tables de l'alimentation des bovins, ovins et caprins. Editions QUAE, Versailles, France.

Jensen, M. D., and M. Kahn. 2001. Blood gas assay performance on the Idexx VetStat Electrolyte and blood gas analyzer. Idexx laboratories, Westbrook, ME.

Laven, R. A., and S. B. Drew. 1999. Dietary protein and the reproductive performance of cows. Vet. Rec. 145:687-695.

Laven, R. A., R. J. Scaramuzzi, D. C. Wathes, A. R. Peters, and T. J. Parkinson. 2007. Recent research on the effects of excess dietary nitrogen on the fertility of dairy cows. Vet. Rec. 160:359-362.

Martin, R. R., G. Eknoyan, C. Saenz, S. E. Hyde 3rd, and J. Olivero. 1979. Effects of renal failure on leukotaxis. J. Med. 10:267-278.

Mehrzad, J., L. Duchateau, S. Pyorala, and C. Burvenich. 2002. Blood and milk neutrophil chemiluminescence and viability in primiparous and pluriparous dairy cows during late pregnancy, around parturition and early lactation. J. Dairy Sci. 85:3268-3276.

Nuutila, J., and E. M. Lilius. 2005. Flow cytometric quantitative determination of ingestion by phagocytes needs the distinguishing of overlapping populations of binding and ingesting cells. Cytometry A 65:93-102.

Oltner, R., M. M. Emanuelson, and H. Witktorsson. 1985. Urea concentrations in milk in relation to milk yield, live weight, lactation number and amount and composition of feed given to dairy cows. Livest. Prod. Sci. 12:47-57.

Oltner, R., and H. Witktorsson. 1983. Urea concentrations in milk and blood as influenced by feeding varying amounts of proteins and energy to dairy cows. Livest. Prod. Sci. 10:457-467.

Ordonez, A., T. J. Parkinson, C. Matthew, C. W. Holmes, R. D. Miller, N. Lopez-Villalobos, J. Burke, and I. Brookes. 2007. Effects of application in spring of urea fertiliser on aspects of reproductive performance of pasture-fed dairy cows. N. Z. Vet. J. 55:69-76.

Raboisson, D., A. Ferrieres, M. C. Nicot, F. Enjalbert, and F. Schelcher 2012a. Experimental soybean meal intoxication in cattle. J. Vet. Intern. Med. 26:393-401.

Raboisson, D., P. Sans, G. Allaire, and E. Cahuzac. 2012b. Positive and negative associations between milk urea and somatic cell counts. Page 160 in Proc. Int. Symp. Vet. Epidemiol. Econ., Maastricht, the Netherlands. Wageningen Acad. Publ., Wageningen, the Netherlands.

Roth, J. A., and M. L. Kaeberle. 1981. Evaluation of bovine polymorphonuclear leukocyte function. Vet. Immunol. Immunopathol. 2:157-174.

Quade, M. J., and J. A. Roth. 1997. A rapid, direct assay to measure degranulation of bovine neutrophil primary granules. Vet. Immunol. Immunopathol. 58:239-248. 
Sardenberg, C., P. Suassuna, M. C. Andreoli, R. Watanabe, M. A. Dalboni, S. R. Manfredi, O. P. dos Santos, E. G. Kallas, S. A. Draibe, and M. Cendoroglo. 2006. Effects of uraemia and dialysis modality on polymorphonuclear cell apoptosis and function. Nephrol. Dial. Transplant. 21:160-165.

Smith, S. L. 1998. Shark complement: An assessment. Immunol. Rev. 166:67-78.

Stevens, M. G., M. E. Kehrli Jr., and P. C. Canning. 1991. A colorimetric assay for quantitating bovine neutrophil bactericidal activity. Vet. Immunol. Immunopathol. 28:45-56.

Suriyasathaporn, W., C. Heuer, E. N. Noordhuizen-Stassen, and Y. H. Schukken. 2000. Hyperketonemia and the impairment of udder defense: A review. Vet. Res. 31:397-412.
Tamminga, S. 2006. The effect of the supply of rumen degradable protein and metabolisable protein on negative energy balance and fertility in dairy cows. Anim. Reprod. Sci. 96:227-239.

Ward, R. A., and K. R. McLeish. 1995. Hemodialysis with cellulose membranes primes the neutrophil oxidative burst. Artif. Organs 19:801-807.

Zarbock, A., M. Schmolke, T. Spieker, K. Jurk, H. Van Aken, and K. Singbartl. 2006. Acute uremia but not renal inflammation attenuates aseptic acute lung injury: A critical role for uremic neutrophils. J. Am. Soc. Nephrol. 17:3124-3131. 